\title{
Numerical Simulation as a Tool to Predict Sheet Metal Forming Process of TRIP Steel HCT690
}

David Koreček, Pavel Solfronk, Jiř́ Sobotka

Faculty of Mechanical Engineering, Technical University of Liberec. Studentská 2, 46117 Liberec. Czech Republic. E-mail: david.korecek@tul.cz, pavel.solfronk@tul.cz, jiri.sobotka@tul.cz

The submitted paper describes the utilization of numerical simulations to predict sheet metal forming process of ultra-high strength TRIP steel HCT690T EN 10346. Numerical simulations of production processes are increasingly becoming an integral part of the pre-production stage of the sheet metal forming processes. Furthermore, it is possible to use these numerical simulations not only in the production itself (e.g. to test the validity of the process or influence of process parameters, etc.), but also in the post-production stage as a tool for various controls and comparative measurements with the real processes, testing the capacity of the process and so on. For proper and the reliable course of the numerical simulation must be at first obtained and then entered the correct input data into the numerical simulation software. This data enters into the simulation in the form of definition the material computational model. Such computational model is defined by using material data and individual material characteristics at different loading methods. With regard to the material model and the given process parameters, it is possible to realize the process simulation, which takes place in the numerical simulation software - in this paper was used PAM STAMP 2G from the French company ESI Group.

Keywords: Numerical Simulation, Sheet Metal Forming, Spring-back, Material Computation Model, Ultra-high Strength Steel

\section{Introduction}

The utilization of the ultra-high strength materials in industrial production is now becoming almost standard. Regarding the today's trends, there is a strong tendency in the automotive industry to continuously reduce exhaust emissions and to observe still increasingly stringent environmental rules and regulations. This fact is associated with requirements to reduce the total weight of car-bodies. Such facts directly encourage the application of the ultra-high strength materials. Three-phase steel or steel with transformation induced plasticity is a material, whose structure is based on a ferritic-bainitic matrix. In this matrix, 5 up to 10 percent of residual metastable austenite is also present in the initial state, which is transformed into martensite during the subsequent deformation process. Specifically, ultra-high strength TRIP steel HCT690T EN 10346 was investigated and used in this paper. $[1,2,3]$

Another great requirement and also trend of toda$y$ 's industrial production is the reduction of production times (so-called "cycle times") and thus maintaining the greatest possible economy of production. This aspect encourages the introduction of numerical simulations into the production process not only in the pre-production stage, but also during the entire own production. So numerical simulations are nowadays becoming an integral part of the production process. However, for the correct course of the numerical simulation, it is necessary to prepare the correct input data, which influence the process of the mathematical computation through the very important definition of the material model. This paper examines the usage of numerical simulation for the sheet metal forming process. Because of simplification and illustration of computation, a simple " $\mathrm{U}$ " shaped stamping is used here. To determine the material characteristics and its properties during the deformation of the material, thre were performed different material tests, which simulate the required stress states (uniaxial and equi-biaxial ones). The obtained material data from these tests are given into the numerical simulation through the definition of the material model in the environment of the software for numerical simulations PAM STAMP 2G. In the numerical simulation, the basic deformation computation of the material in the tool during the production of the stamping takes place and subsequently is performed the simulation of the material spring-back, which occurs after releasing the loading force of punch. In order to be able to prove the validity of the numerical simulation results or to perform the so-called compensation, the resulting contour of the stamping obtained from the numerical simulation is finally compared with the contour of the real stamping. $[4,5,6]$ 


\section{Experimental part}

\subsection{Static Tensile Test}

The static tensile test was carried out in order to ensure a uniaxial tensile load in the deformed body and was performed using a TIRA Test 2300 testing machine. As a testing specimen there was used a standardized testing rod with dimensions $\mathrm{l}_{0}=80 \mathrm{~mm}$, $\mathrm{b}_{0}$ $=20 \mathrm{~mm}$ and $\mathrm{t}_{0}=1.14 \mathrm{~mm}$. The testing specimens for the test were prepared in selected directions $0^{\circ}, 45^{\circ}$ and $90^{\circ}$ with respect to the rolling direction. The course of the test was monitored by means of a strain- gauge sensor connected to the clamping jaws of a testing machine (which ensures to measure the force during the test) and by an integrated extensometer XXX, by means of which the change in length of the testing specimen was monitored. The measured values of force $\mathrm{F}$ and absolute elongation (changes in the len$\mathrm{gth}$ ) of the testing specimen in the measured area were further recalculated on the dependence of the engineering stress $\mathrm{R}$ and engineering strain $\varepsilon$. These dependences for every direction are illustrated in the graph in Figure 1.

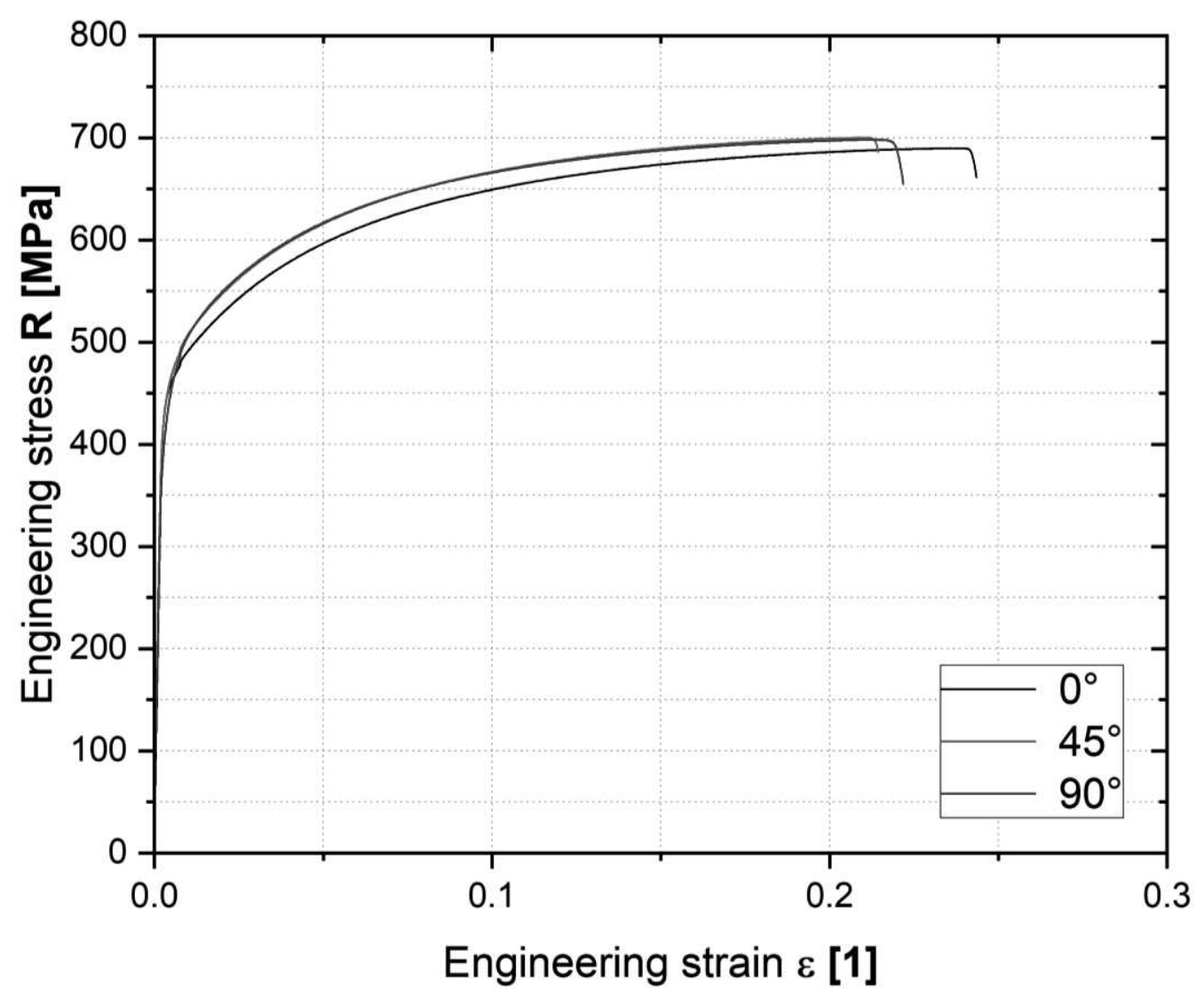

Fig. 1 Representation of the dependence of engineering stress and strain with respect to the individual rolling direction

The static tensile test was used here to obtain the basic mechanical properties of tested material. The values of the ultimate strength $R_{\mathrm{m}}$ and the proof yield strength $R_{\mathrm{p} 0.2}$ were determined by this test, as well as the values of the Young's tensile modulus E, the coefficients of normal anisotropy $\mathrm{r}_{\mathrm{i}}$, total ductility $A_{80}$ and uniform ductility Ag. The resulting values of mechanical properties in individual directions (regarding the rolling direction) obtained as an arithmetic mean and determined from 3 measurements are shown below in Table 1.

Tab. 1 Basic results from the static tensile in given directions

\begin{tabular}{|c|c|c|c|c|c|c|}
\hline $\begin{array}{c}\text { Rolling } \\
\text { direction } \\
{\left[^{\circ}\right]}\end{array}$ & $\begin{array}{c}\mathbf{E} \\
{[\mathrm{MPa}]}\end{array}$ & $\begin{array}{c}\mathbf{r}_{\mathrm{i}} \\
{[1]}\end{array}$ & $\begin{array}{c}\mathbf{R}_{\mathrm{p} 0,2} \\
{[\mathrm{MPa}]}\end{array}$ & $\begin{array}{c}\mathbf{R}_{\mathrm{m}} \\
{[\mathrm{MPa}]}\end{array}$ & $\begin{array}{c}\mathbf{A}_{\mathbf{g}} \\
{[\%]}\end{array}$ & $\begin{array}{c}\mathbf{A}_{80 \mathrm{~mm}} \\
{[\%]}\end{array}$ \\
\hline 0 & \multirow{3}{*}{191338.250} & 0.818 & 456.085 & 689.960 & 23.445 & 24.860 \\
\hline 45 & & 0.749 & 456.220 & 699.620 & 21.850 & 22.925 \\
\hline 90 & & 1.131 & 436.655 & 696.575 & 21.145 & 22.815 \\
\hline
\end{tabular}


To define the material model in the numerical simulation, it was also necessary to determine the strength coefficient $C$, strain hardening exponent $n$ and offset of strain $\varphi_{0}$. These values were subsequently determined by fitting stress-strain curves according the Krupkovsky hardening law - see Equation 1. The values obtained from these approximation constants are shown in Table 2.

$$
\sigma=C .\left(\varphi+\varphi_{0}\right)^{n}[M P a],
$$

$$
\begin{aligned}
& \text { Where: } \\
& \text { C...strength coefficient [MPa], } \\
& \text { n...strain hardening exponent [1], } \\
& \varphi_{0} \ldots \text { offset of strain [1]. }
\end{aligned}
$$

Tab. 2 Approximations constants acc. to Krupkovsky hardening law from the static tensile test

\begin{tabular}{|c|c|c|c|}
\hline $\begin{array}{c}\text { Rolling } \\
\text { direction } \\
{\left[{ }^{\circ}\right]}\end{array}$ & $\begin{array}{c}\mathbf{C} \\
{[\mathbf{M P a}]}\end{array}$ & $\begin{array}{c}\mathbf{n} \\
{[-]}\end{array}$ & $\begin{array}{c}\boldsymbol{\varphi}_{\mathbf{0}} \\
{[-]}\end{array}$ \\
\hline 0 & 1213.670 & 0.23719 & 0.01597 \\
\hline 45 & 1207.034 & 0.22210 & 0.01399 \\
\hline 90 & 1193.280 & 0.21466 & 0.01255 \\
\hline
\end{tabular}

\subsection{Hydraulic Bulge Test (HBT)}

The hydraulic bulge test (sometimes termed as equi-biaxial stretching of material by means of hydraulic pressure) was performed to induce a equi-biaxial state of stress in the deformed workpiece and thus to obtain the necessary material characteristics under this type of loading. The test was done on a hydraulic press CBA300/63, where the sample was at first clamped by a blank-holding force and subsequently deformed by the hydraulic pressure. The course of such "control" pressure during the whole test was monitored by means of a pressure sensor connected to the machine control unit and own deformation of the sample was monitored by the contact-less optical system MERCURY RT from company Sobriety, Ltd. In order to be able to optically scan the deformation, the sample had to be provided with a special spray, which creates a so-called pattern (stochastic pattern). This pattern is then able to be recorded by the optical system by dividing it into so-called facets of a defined size in pixels, which is assigned a certain degree of grey and their position is scanned during the test.

The dependence of the effective stress vs. effective deformation was subsequently calculated from the measured values and again, there was used fitting of this curve according the Krupkovsky hardening law (see Equation 1). The approximated stress-strain curve can be seen in Figure 2. As an output from HBT, which is used to define the material model in the numerical simulation, there are also approximation constants $\mathrm{C}, \mathrm{n}$ and $\varphi_{0}$. However, in this case correspond these constants to the equi-biaxial stress state of material. These constants are shown in Table 3.

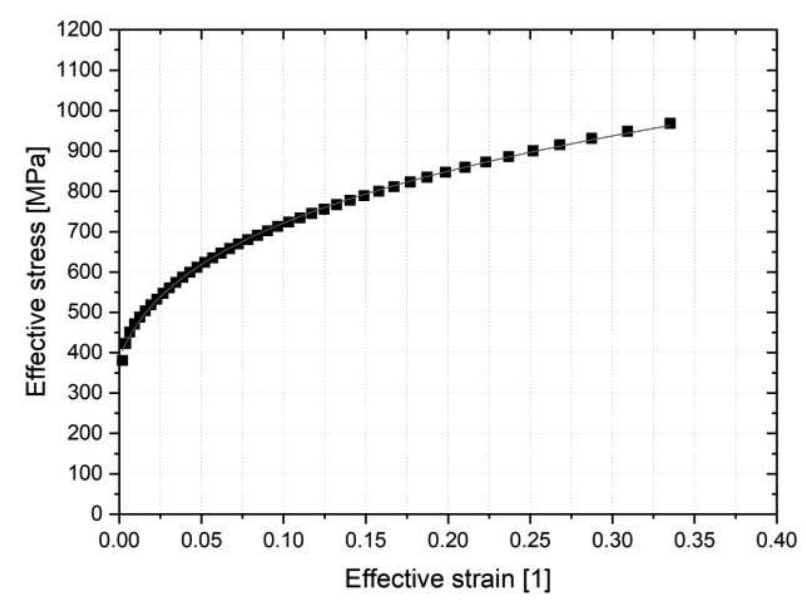

Fig. 2 Example of Krupkowsky approximation of stressstrain curve from HBT

Tab. 3 Approximations constants acc. to Krupkovsky hardening law from the bydraulic bulge test

\begin{tabular}{|c|c|c|c|}
\hline $\begin{array}{c}\text { Rolling } \\
\text { direction } \\
{\left[{ }^{\circ}\right]}\end{array}$ & $\begin{array}{c}\mathbf{C} \\
{[\mathbf{M P a}]}\end{array}$ & $\begin{array}{c}\mathbf{n} \\
{[-]}\end{array}$ & $\begin{array}{c}\boldsymbol{\varphi}_{0} \\
{[-]}\end{array}$ \\
\hline- & 1257.736 & 0.25055 & 0.00887 \\
\hline
\end{tabular}

\subsection{U-die sheet metal forming}

A real experiment of sheet metal forming into a "U" shape was performed in order to obtain a comparative standard for the numerical simulation. The "U" forming tool consisted of a simple punch, die and blank-holder. Using this tool clamped in a TIRA Test 2300 testing machine, a real stamping was made (see Figure 3 - left). Such stamping had to be subjected to analysis to obtain its true contour after own forming and its subsequent spring-back. This was realized by means of a 3D measuring coordinate device SOMET XYZ 464 and software TANGO!3D. By using such device, individual points along the plane of the stamping were scanned and then were fitted with a curve representing the contour of this real stamping. The curve was subsequently exported and was used to compare the resulting contours determined from the numerical simulation. The contour scanning via using a 3D measuring device can be seen in Figure 3 - right. 


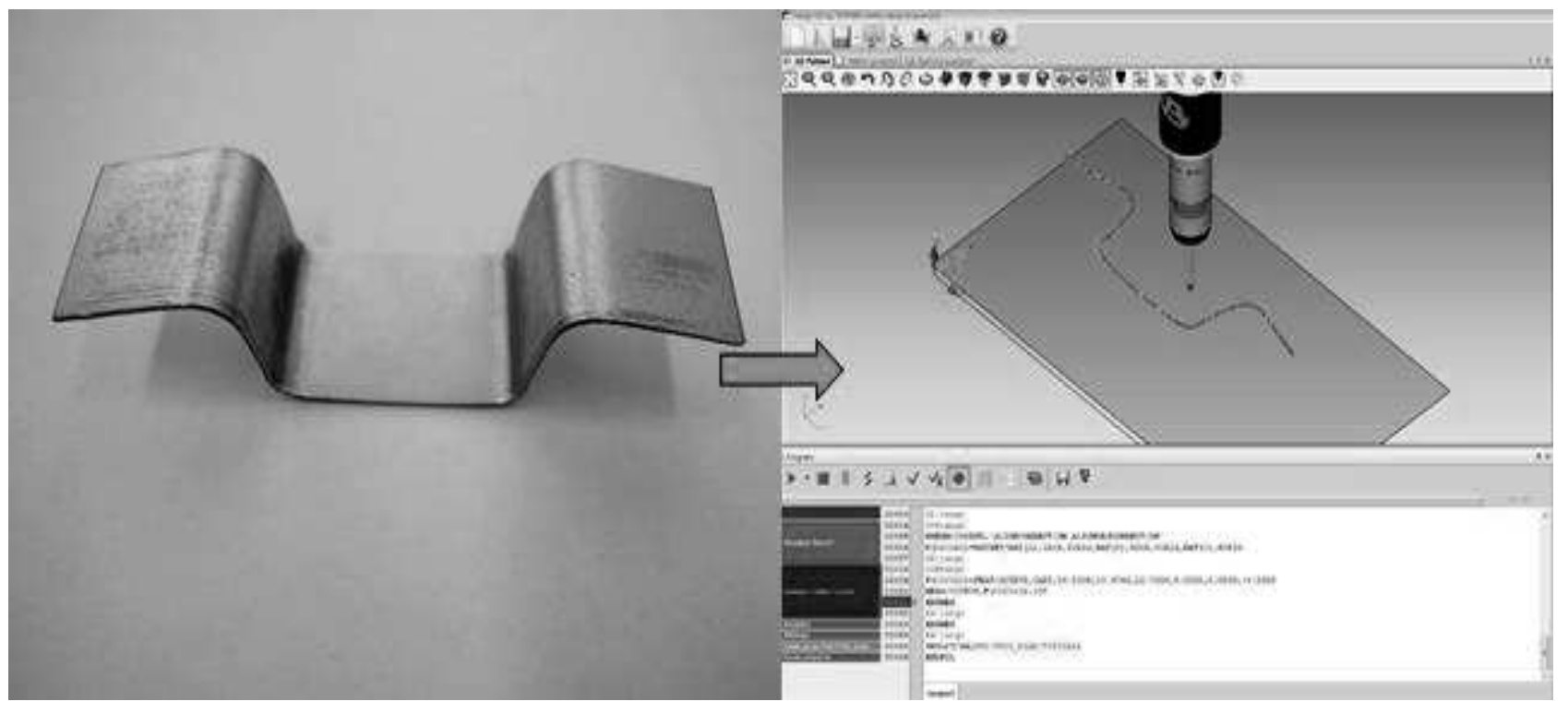

Fig. 3 Specimen from U-die sheet metal forming (left) and generated contour curve from 3D measuring device

\section{Numerical simulation}

Mechanics of flexible bodies and finite element methods are used as fundamental tools for numerical simulations computations. Currently, the finite element method (FEM) is considered to be the most powerful tool for mathematical modelling in numerical simulations. For numerical simulations, software PAM STAMP 2G is used here, which is a specialized CAE software designed for simulation, especially of the sheet metal forming processes. In principle, the individual components that participate in the simulation computation are in the form of CAD model transferred to the computation mesh of the CAE model. The same principle is used in the case of sheet blank, which is subsequently deformed in the numerical simulation. The computational mesh is generated by a graphical pre-processor together with the boundary, contact and loading conditions necessary for solving a mathematical problem simulating a real deformation process. $[6,7,8]$

Generally, numerical simulation will work efficiently and provide valid results only if the whole simulated process is correctly defined at the beginning. It is therefore necessary to precisely define the tool geometry corresponding to the real process, shape and dimensions of the sheet blank and the material data and characteristics that enter the simulation in the form of a material model. As another integral part, there is the correct and accurate setting of boundary conditions and process parameters of the simulated task. $[7,8]$

\subsection{Definition of the material model}

The Vegter Lite model with isotropic hardening of the material was used as a mathematical computational model for numerical simulation in the environment of the software PAM STAMP 2G. This model can be also used for anisotropic materials, but it requires more complex measurements of material properties. The basic parameters to define the Vegter Lite model are the physical material properties such as e.g. density $\varrho$ and Poisson's ratio $\mu$, as well as the individual material characteristics obtained from the material testing under different types of loading. From the static tensile test, the Young's tensile modulus, normal anisotropy coefficients in the individual directions, strength characteristics of the material and approximation constants arising from the fitting by the Krupkovsky hardening law were obtained. In addition to that, material characteristics under equi-biaxial loading, equibiaxial anisotropy coefficient and again approximation constants were obtained by using HBT.

The Vegter Lite model with kinematic hardening of the material was used as the next mathematical computational model for numerical simulation. This model can be also used for anisotropic materials. In this case, the Baschinger effect is considered. The values of constants for defining the kinematic hardening of the material were determined by Mathwizard software from the company ESI GRoup. The definition of this material model can be seen in Figure 5. 


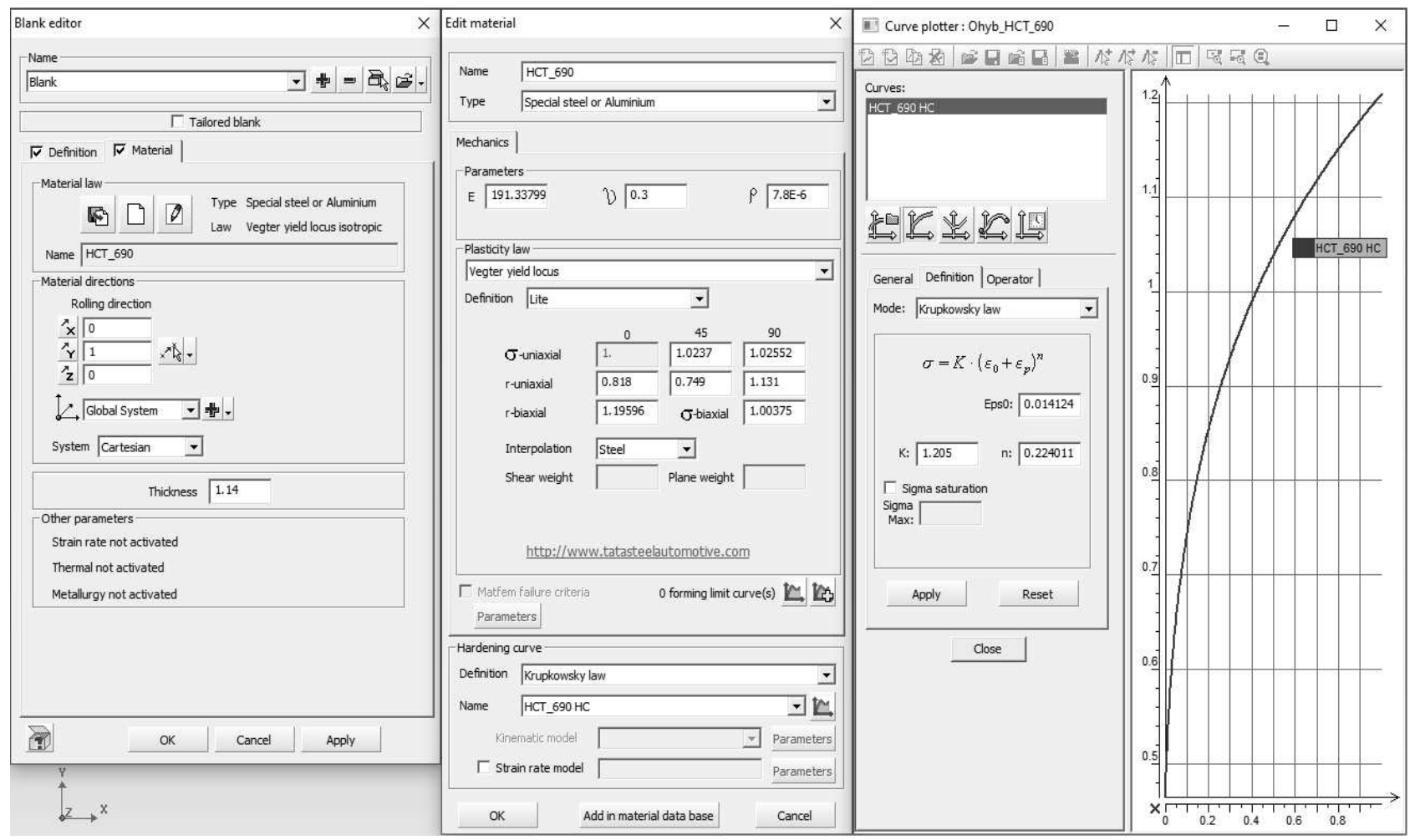

Fig. 4 Definition of the material model with isotropic hardening of the material in software PAM STAMP 2G

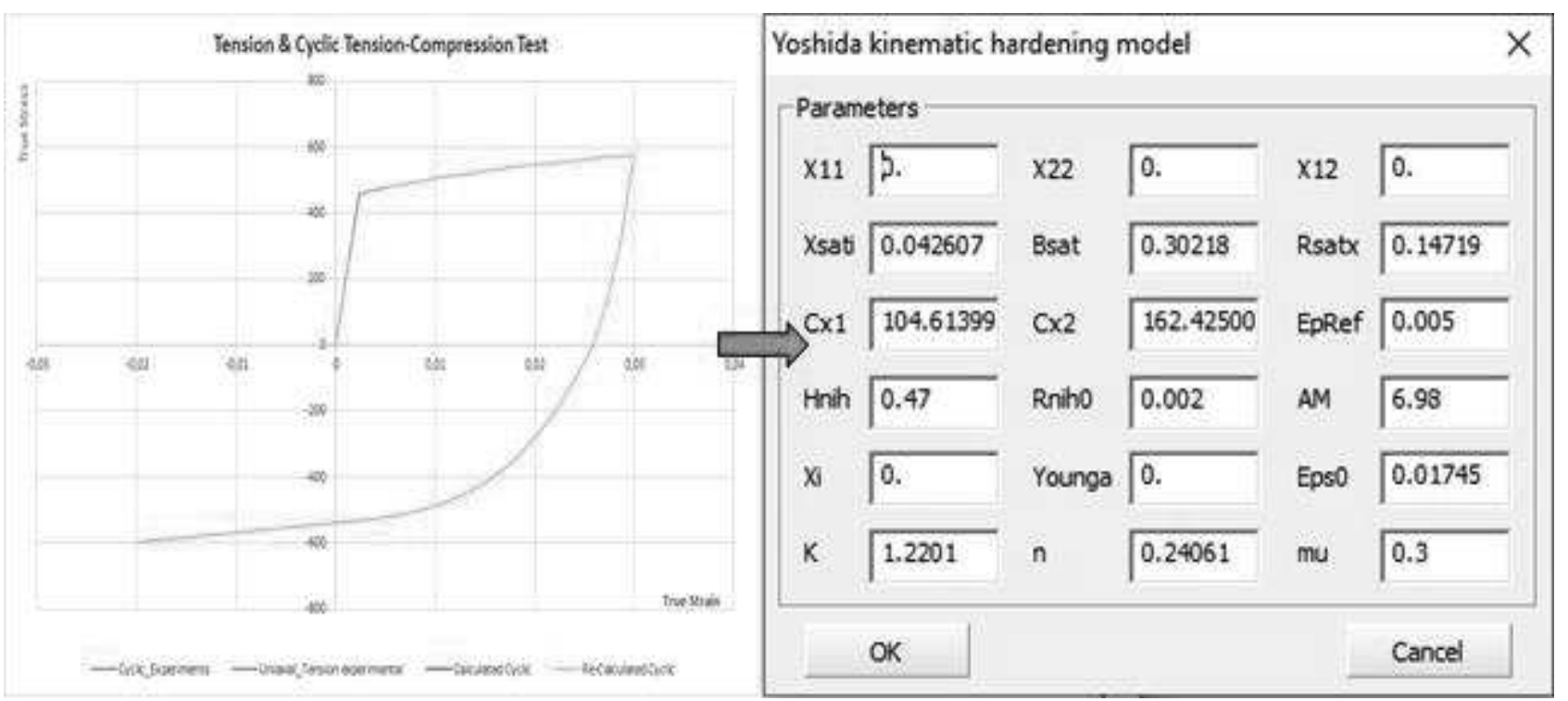

Fig. 5 Definition of the material model with kinematic hardening of the material in software PAM STAMP 2G

\subsection{Definition of the FEM project}

Setting up a finite element method in a software environment consists of defining a material model (see the previous chapter), importing the parts of the tool that participate in the simulated deformation process and setting other process parameters of the given task. The corresponding tool geometry was made in the CAD software CATIA V5 in the form of surface, which was subsequently imported into the software PAM STAMP 2G. At first, there was necessary to place the imported parts of the tool in the correct mutual positions and to properly orient the normal to surfaces. After that it was possible to import the sheet blank, which is subjected to the computation of deformation and subsequent spring-back. First, the deformation process, where the blank under the given conditions was drawn into the die, was simulated and subsequently after the end of the deformation due to the action of the tool (unloaded state), the material springback due the elastic deformation was computed. 


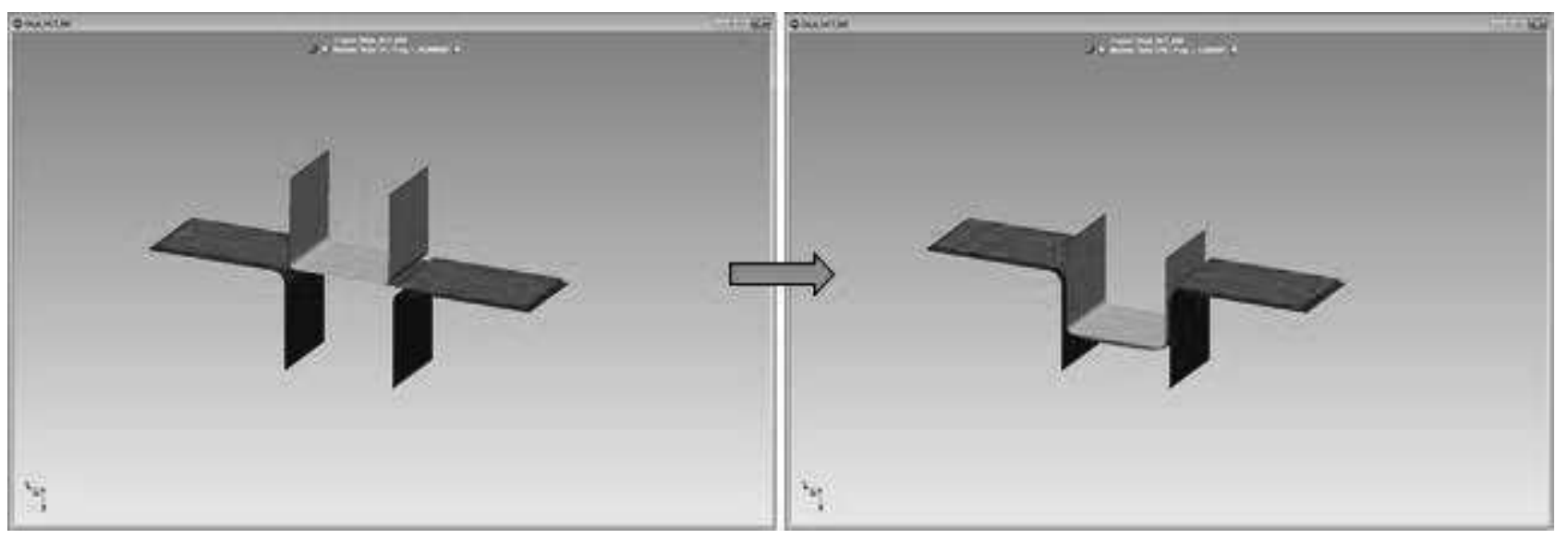

Fig. 6 Definition of the FEM project in software PAM STAMP $2 G$

\section{Results}

The numerical simulation was performed according to the Vegter Lite model with regard to the parameters of the real production process. Graphical results of the numerical simulation are given below. In
Figure 7 is shown deformation of the simulated sheet during the numerical simulation of this sheet metal forming process and the subsequent spring-back after the deformation due to its release from the tool.
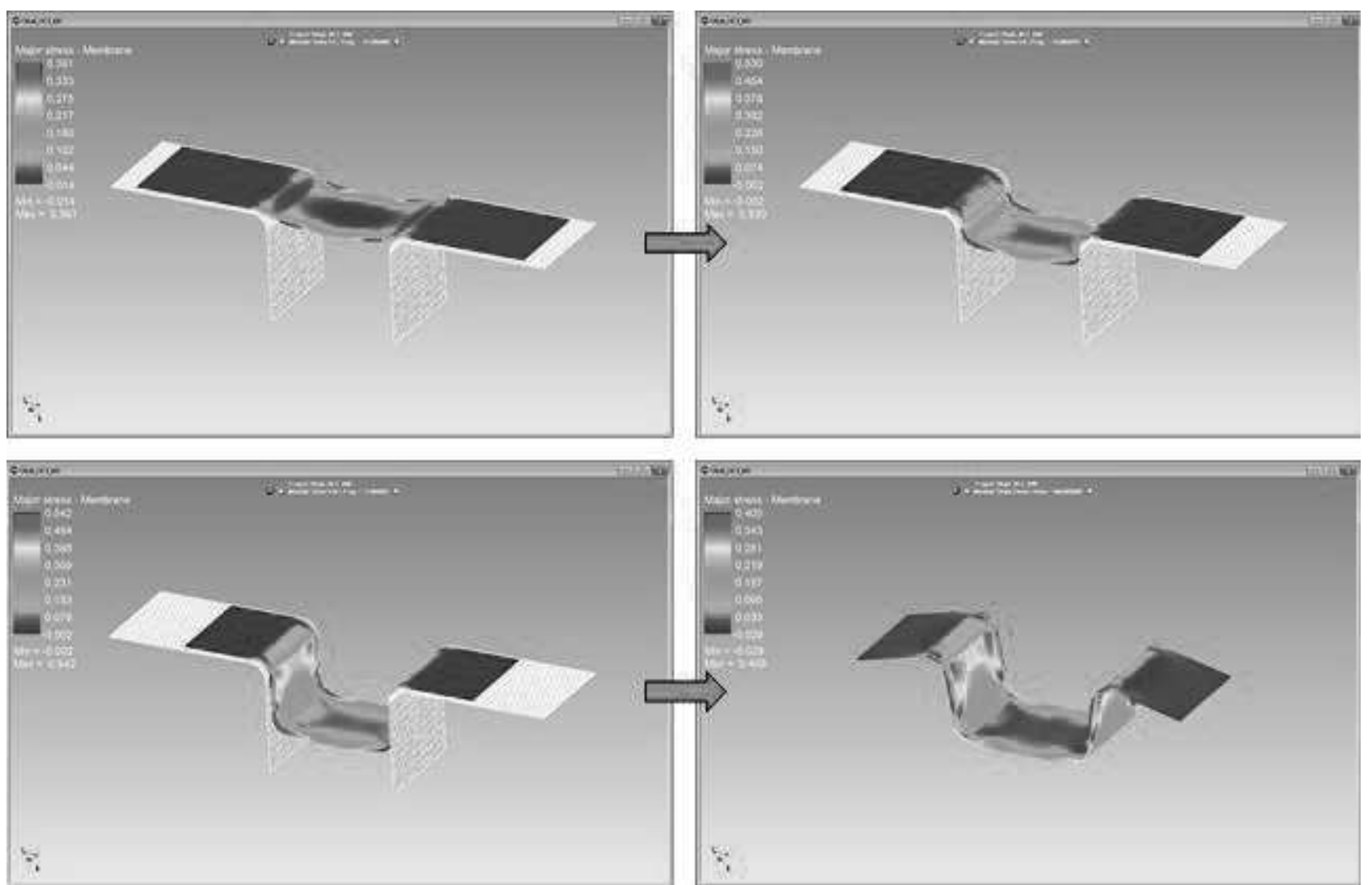

Fig. 7 deformation of the simulated sheet during the numerical simulation in software PAM STAMP 2G

Figure 8 shows a comparison between results from the numerical simulation and the real production process of given sheet metal stamping. The resulting contours of stampings (obtained from the numerical simulation and real production process in its final state) are graphically displayed and compared, i.e. after spring-back of the tested material. The resulting contour obtained from the numerical simulation is given in red (Isotropic hardening) and green (Kinematic hardening- Yoshida model). The resulting contour obtained by the real production process in given in blue. 


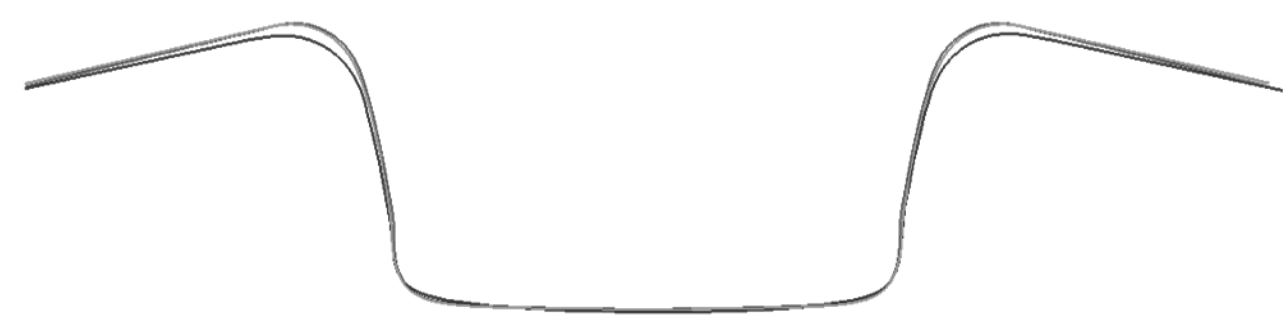

\section{Vegter Lite Isotropic}

\section{Vegter Lite Yoshida}

Real Experiment

Fig. 8 Comparison of numerical simulation Vegter Lite model and real experiment

\section{Conclusion}

The major aim of this paper was to evaluate and assess the utilization of numerical simulation as a tool to predict the complex sheet metal forming process (thus including the final spring-back) of the ultra-high strength steel TRIP Steel HCT 690T. In order to be able to mathematically define the whole tested process, it was necessary at first to perform material testing to determine the required material characteristics. This material testing is described in Chapter 2. Chapter 3 then describes the performance of a numerical simulation, which corresponds to the real production process for stampings of this shape. The resulting contours of the tested stamping from the simulation and from the real production process are compared in Chapter 4. In comparison of the real contour and Vegter Lite Isotropic model, deviations can be seen, which are caused by not considering the kinematic hardening of the tested material (so-called Bauschinger effect). In comparison of the real contour and Vegter Lite Kinematic-Yoshida model, which are considering the Bauschinger efect, there can be seen small improvement of accuracy the contour from numerical simulation in PAM STAMP 2G.

\section{Acknowledgement}

This work was [partly] supported by the Student Grant Competition of the Technical University of Liberec under the project No. SGS-2019-5046.

\section{References}

[1] DAVIES, G. (2003). Materials for Automobile Bodies. Oxford: Butterworth-Heinemann, 2003. s. 277. ISBN 0-7506-5692-1.

[2] HOSFORD, W.F., CADDEL, R. (2007). Metal Forming (Mechanics and Metallurgy). 3rd ed. New
York: Cambridge University Press, 2007. s. 312. ISBN 978-0-521-88121-0.

[3] KUČEROVÁ, L., et al. (2019). Microstructure Analysis and Mechanical Properties of Low Alloyed Steel with Retained Austenite Obtained by Heat Treatment. Manufacturing Technology, Vol. 19(2), pp 243-247. ISSN 1213-2489

[4] JANDA, T., et al. (2019). Influence of Cooling Rate on Microstructure and Mechanical Properties of 42SiCr Steel after Q\&P Process. Manufacturing Technology, Vol. 19(4), pp 583-588. ISSN 1213-2489

[5] CHOVANEC, A., BREZNICKÁ, A. (2017). Some aspects of a manufacturing process simulation. Manufacturing Technology, Vol. 17(3), pp 319-325. ISSN 1213-2489

[6] SU, CHUNJIAN, WANG, XUETAO. (2014). Sprinkback Research of V-type Sheet Metal forming based on the Adjustable Drawbead and Variable Blank-holder Force Cooperative Control Technology. Manufacturing Technology. Vol. 14. pp 618-625. ISSN ISSN 1213-2489

[7] SHUN-LAI, Z., et al. (2013). Evaluating the significance of hardening behavior and unloading modulus under strain reversal in sheet springback prediction. International Journal of Mechanical Sciences, December 2013, Vol. 77, pp 194-204. ISSN 0020-7403.

[8] TAHERIZADEH, A., et al. 2009). Finite element simulation of springback for a channel draw process with drawbead using different hardening models. International Journal of Mechanical Sciences, April 2009, Vol. 51, No. 4., pp 314-325. ISSN 0020-7403. 